\title{
Radiomic Imaging Analysis-To Renovate RECIST Criteria?
}

\author{
*G Lohith, Shivkumar Swamy Shivalingappa and Basavalinga Ajai Kumar \\ Healthcare Global Enterprises limited, Bangalore, India
}

Submission: July 15, 2017; Published: July 18, 2017

*Corresponding author: G Lohith, Consultant Radiation Oncologist, Chief Director-Radiomics and Radiogenomics, Healthcare Global Enterprises Limited, Bangalore, India, Email: lampard_buddyy@hotmail.com

\section{Short Communication}

Medical imaging is often used in clinical practice for oncological diagnosis, staging and treatment guidance [1]. Imaging in "personalized medicine", helps in tailoring the treatment on the basis of specific characteristics of the patient and their disease [2]. Tumors are spatially and temporally heterogeneous, requiring biopsies or invasive surgeries to extract and analyze what are generally small portions of tumour tissue, which do not allow for a complete characterization of the tumor. Imaging provides a comprehensive view of the entire tumor and can be used on an ongoing basis to dynamically monitor the development and progression of the tumor or its response to therapy. Contrary of genomics or proteomics, Imaging is noninvasive and is repeated during treatment which is easy implemented in clinical practice.

In clinical practice, tumors are described based on one or two-dimensional descriptors of tumor size (RECIST Criteria). Although a change in tumor size can indicate response to cancer treatment, it often does not always predict overall or progression free survival [3]. However with recent advances in image acquisition, standardization and image analysis allow for objective and precise quantitative imaging descriptors that could potentially be used as noninvasive prognostic or predictive biomarkers.

Radiomics is an emerging field that converts imaging data into a high dimensional mineable feature space using a large number of automatically extracted data-characterization algorithms [4]. Analysis of image features in CT scans and PET scans has been a largely studied field and extensive literature exists. However, majority of work describes usage of imaging features focused in detection of small nodules in, for example, mammograms or chest $\mathrm{CT} /$ positron emission tomography (PET) scans, or in the differential diagnosis of malignant versus benign nodules (computed-aided diagnostics). Radiomics based quantitative imaging is a new dynamic field which could be corelated with large amount of available data of clinical parameters, gene expression profiles and other prognostic and predictive markers to further validate the optimum value of Precision and personalized medicine in cancer therapy $[5,6]$.

\section{Problem Statement}

Huge variability in image acquisition exists across hospitals and there is no standardization of image acquisition across centers to arrive and extract common radiomic features. However, The data can be directly generated from the scanner and the features can be calculated from the RAW imaging data, without any pre-processing or normalization and can be used as a strong argument in favour of a multi-centric application of radiomics across the world. The power of radiomics will even further improve with better and robust standardization and imaging protocols. Among others, the quantitative imaging network of the National Institute of Health (NIH), as well as the quantitative imaging biomarker alliance, investigates future directions by performing phantom studies and discussing with vendor's open and standardized protocols for image acquisition $[1,7]$.

Radiomics can have a large clinical impact, as imaging is used in routine practice worldwide, providing a method that can quantify and monitor phenotypic changes during treatment providing an unprecedented opportunity to improve decisionsupport in cancer treatment at low cost and can bring about a major change in thinking of clinicians who classify, stage, treat and assess tumor responses based on TNM and "RECIST" Criteria to in-turn advocate the smooth transition from evidence based medicine to Precision and personalized medicine. 


\section{References}

1. Kurland BF, Gerstner ER, Mountz JM, Schwartz LH, Ryan CW, et al (2012) Promise and pitfalls of quantitative imaging in oncology clinical trials. Magn Reson Imaging 30(9): 1301-1312.

2. Lambin P, Van Stiphout RG, Starmans MH, Rios Velazquez E, Nalbantov G, et al. (2013) Predicting outcomes in radiation oncology-multifactorial decision support systems. Nat Rev Clin Oncol 10(1): 27-40.

3. Burton A (2007) RECIST: right time to renovate? Lancet Oncol 8(6): 464-465.

4. Kumar V, Gu Y, Basu S, Breglund A, Eschrich SA, et al. (2012) Radiomics: the process and the challenges. Magn Reson Imaging 30(9): 12341248.
5. Naqa El I, P Grigsby, A Apte, E kidd, E Donnelly, et al. (2009) Exploring feature-based approaches in PET images for predicting cancer treatment outcomes. Pattern Recognit 42(6): 1162-1171.

6. Nair VS, Gevaert O, Davidzon G, Napel S, Graves EE, et al. (2012) Prognostic PET 18F-FDG uptake imaging features are associated with major oncogenomic alterations in patients with resected non-small cell lung cancer. Cancer Res 72(15): 3725-3734.

7. Buckler AJ, Bresolin L, Dunnick NR, Sullivan DC, Group (2011) A collaborative enterprise for multi-stakeholder participation in the advancement of quantitative imaging. Radiology 258(3): 906-914.
This work is licensed under Creative Commons Attribution 4.0 License

DOI: 10.19080/CTOIJ.2017.06.555679

\section{Your next submission with Juniper Publishers will reach you the below assets}

- Quality Editorial service

- Swift Peer Review

- Reprints availability

- E-prints Service

- Manuscript Podcast for convenient understanding

- Global attainment for your research

- Manuscript accessibility in different formats ( Pdf, E-pub, Full Text, Audio)

- Unceasing customer service

Track the below URL for one-step submission https://juniperpublishers.com/online-submission.php 